\title{
COMTVal 108/I58 Met polymorphism and treatment response to aripiprazole in patients with acute schizophrenia
}

This article was published in the following Dove Press journal:

Neuropsychiatric Disease and Treatment

\author{
Haruka Kaneko ${ }^{1,2}$ \\ Itaru Miural \\ Keiko Kanno-Nozaki \\ Sho Horikoshi' \\ Mizuki Hino' \\ Hirooki Yabe' \\ 'Department of Neuropsychiatry, \\ Fukushima Medical University \\ School of Medicine, Fukushima, \\ Japan; ${ }^{2}$ Department of \\ Neuropsychiatry, Hoshi General \\ Hospital, Fukushima, Japan
}

\begin{abstract}
Introduction: The COMT Val 108/158 Met polymorphism (rs4680) may affect treatment response to antipsychotics, as well as metabolism and dynamics of neurotransmitters during the treatment of schizophrenia. We investigated the effects of the COMT Val 108/158 Met polymorphism on treatment response to aripiprazole and plasma monoamine metabolite levels in patients with acute schizophrenia.
\end{abstract}

Materials and methods: Forty patients with schizophrenia were treated with aripiprazole for 6 weeks. We measured Positive and Negative Syndrome Scale (PANSS) and plasma levels of homovanillic acid (HVA) and plasma MHPG (3-methoxy-4-hydroxyphenethyleneglycol) at baseline and endpoint. The COMT Val 108/158 Met polymorphism was genotyped with the polymerase chain reaction and restriction fragment length polymorphism.

Results: There were significant genotype-time interactions on PANSS total and general psychopathology scores, with Met/Met genotype showing greater improvement. The response rate to aripiprazole did not differ between COMT Val 108/158 Met genotype groups. We found a significant time effect on plasma MHPG levels, but no time effect on plasma HVA levels or time-genotype interactions in the plasma levels of HVA and MHPG. Although the responder rate did not differ among the 3 genotype groups.

Conclusion: Our results suggest that individuals with the Met/Met genotype had greater improvement in PANSS score after the treatment with aripiprazole. On the other hand, the Val 108/158 Met polymorphism may not induce changes in plasma levels of monoamine metabolites during aripiprazole treatment. Because of the small sample size, further studies are needed to confirm and to extend our results.

Keywords: schizophrenia, COMT, Val 108/158 Met polymorphism (rs4680), aripiprazole, pharmacogenetics

\section{Introduction}

Although antipsychotics play a critical role in the treatment of schizophrenia, there are considerable interindividual differences in the treatment response to antipsychotics. Pharmacogenetic studies have focused on various genes to identify meaningful predictors for treatment response to antipsychotics. Previous meta-analyses showed significant associations between the treatment response to antipsychotics and the $-141 \mathrm{C}$ Ins/del (rs1799732) polymorphism in $D R D 2,{ }^{1}$ the T102C (rs6313) polymorphism in $5 H T 2 A,{ }^{2}$ the $\mathrm{C} 1019 \mathrm{G}$ (rs6295) polymorphism in $5 H T 1 A,{ }^{3}$ and Val $108 / 158 \mathrm{Met}$ (rs4680) polymorphism in COMT. ${ }^{4}$

COMT methylates neurotransmitters, such as dopamine and noradrenaline, and drugs such as L-dopa. COMT is positioned in the q11.21 on chromosome 22 and has various
Correspondence: Itaru Miura

Department of Neuropsychiatry,

Fukushima Medical University

School of Medicine, I Hikarigaoka,

Fukushima 960-1295, Japan

$\mathrm{Tel}+8 \mid 24547$ |33|

Fax +8I 245486735

Email itaru@fmu.ac.jp 
single-nucleotide polymorphisms (SNPs). One base of the 108/158th codon replaces $G$ with $A$, which changes valine to methionine. ${ }^{5}$ The activity of the Val allele enzyme is 3- to 4-fold higher than that of the Met allele enzyme, ${ }^{6}$ and this SNP may affect the dynamics of neurotransmitters and the antipsychotic response. A recent meta-analysis showed that individuals with Met/Met genotype were associated with favorable response to atypical antipsychotics. ${ }^{4}$ This meta-analysis included both positive $^{7-10}$ and negative $\mathrm{e}^{1-14}$ studies regarding the association between the Val 108/158 Met genotype and treatment response to antipsychotics. However, the meta-analysis did not include studies with aripiprazole, which has a unique pharmacological profile as a partial agonist for dopamine D2 receptors. Furthermore, the underlying biological basis of the association between the Val 108/158 Met genotype and treatment response to antipsychotics remains unclear.

Homovanillic acid (HVA) and plasma MHPG (3-methoxy4-hydroxyphenethyleneglycol) are the main metabolites of dopamine and noradrenaline, respectively. Plasma levels of HVA and MHPG reflect $30 \%-50 \%$ of $\mathrm{HVA}^{15}$ and one-third of $\mathrm{MHPG}^{16}$ in the central nervous system, respectively. Although it is difficult to regard plasma monoamine metabolites as direct reflections of central nervous system activity, plasma HVA levels are considered a possible indicator of the clinical response to antipsychotic drugs. ${ }^{17}$ Furthermore, plasma HVA levels parallel improvement in positive symptoms during treatment of schizophrenia. ${ }^{18}$

Because no studies have examined the association between the COMT Val 108/158 Met polymorphism and treatment response to aripiprazole and because the genotype effects on monoaminergic neurotransmission during antipsychotic treatment remains unknown, we investigated the effects of the COMT Val 108/158 Met polymorphism on treatment response to aripiprazole and on plasma monoamine metabolite levels in patients with acute schizophrenia.

\section{Materials and methods}

The subjects were Japanese patients who were diagnosed with schizophrenia according to the Diagnostic and Statistical Manual of Mental Disorders, fourth edition (DSM-IV). Subjects included both drug-naïve and drug-free recurrent patients who had received no antipsychotic drugs (neither oral nor long-acting injection) for at least 2 weeks before entry into this study. For inclusion in this study, patients had to have a Positive and Negative Syndrome Scale (PANSS) total score of at least 80 and minimum score of 4 on at least 2 psychotic item subscales (hallucination, delusion, conceptual disorganization, and suspiciousness). Patients who abused alcohol/drugs and/or those who had organic brain disorders were excluded. Patients received $18 \mathrm{mg} / \mathrm{d}$ aripiprazole on day 1 . From day 2 to the endpoint, physicians regulated the doses of aripiprazole carefully based on the clinical symptoms. Benzodiazepines and anticholinergics were permitted as additional medications to manage insomnia, restlessness, and extrapyramidal symptoms. The efficacy of the treatment was evaluated using PANSS, the Clinical Global Impression (CGI)-S (Severity), and CGI-I (Improvement) Scale. Patients with a CGI-I score of 1 or 2 or a $\geq 30 \%$ decrease from baseline in the PANSS total score were defined as responders.

Blood samples were obtained before breakfast at 0 and 6 weeks after aripiprazole administration. Concentrations of plasma monoamine metabolites were analyzed with highperformance liquid chromatography with electrochemical detection. Plasma levels of HVA and MHPG were analyzed using the methods of Watanabe et al. ${ }^{19}$ The intra-assay coefficients of variation for plasma HVA and MHPG in our laboratory were $3.2 \%$ and $3.1 \%$, respectively. The interassay coefficients of variation for plasma HVA and MHPG were $8.6 \%$ and $7.6 \%$, respectively. Genomic DNA was extracted from white blood cells from patients, and the Val 108/158 Met genotype in COMT was determined with the polymerase chain reaction and restriction fragment length polymorphism method as previously described..$^{20}$ The amplification program included initial denaturation at $95^{\circ} \mathrm{C}$ for 3 minutes, followed by 30 cycles of $58^{\circ} \mathrm{C}$ for 30 seconds, $72^{\circ} \mathrm{C}$ for 1 minutes, and $95^{\circ} \mathrm{C}$ for 30 seconds, followed by a final extension at $72^{\circ} \mathrm{C}$ for 10 minutes. Nla III was added to the polymerase chain reaction products $(217 \mathrm{bp})$, and samples were incubated at $37^{\circ} \mathrm{C}$ for 60 minutes. Samples were then electrophoresed on $4 \%$ agarose gels (Wako Agarose Xp, Wako Pure Chemical Industries Ltd, Osaka, Japan) and visualized with UV. Following amplification and Nla III digestion, the Val/Val genotype yielded bands of 136 and $81 \mathrm{bp}, \mathrm{Val} / \mathrm{Met}$ yielded bands of 136, 96, 81, and $40 \mathrm{bp}$, and Met/Met yielded bands of 96, 81, and $40 \mathrm{bp}$. This study was approved by the ethics committee of Fukushima Medical University, and the patients provided written informed consent after having been informed of the purpose of the study.

We investigated the genotype effects on treatment response (responder rate and changes in PANSS scores) and on plasma levels of monoamine metabolites. Furthermore, we performed responder versus nonresponder comparison. Oneway analysis of variance (ANOVA) was used to compare the patient's demographics (age, duration of illness, etc.), each PANSS score, and the plasma levels of HVA and MHPG among genotypes. The $\chi^{2}$ test was used to compare the sex 
ratio. The last observation carried forward method was used when a dropout occurred. Repeated-measures ANOVA was used to compare the genotypes, treatment period, changes in the PANSS score, and plasma monoamine metabolite levels. The significance level was defined as $p<0.05$. All statistical analyses were performed using IBM SPSS Statistics 23 (IBM Corporation, Armonk, NY, USA).

\section{Results}

Of the 40 patients, 39 patients completed the study, and 1 patient dropped out at week 4 because of a lack of efficacy based on the physician's clinical decision. Among the 40 patients, $16(40.0 \%)$ were responders (Table S1). At the endpoint, doses of aripiprazole ranged from 9 to $30 \mathrm{mg} / \mathrm{d}$ (mean $\pm \mathrm{SD}=24.33 \pm 6.33 \mathrm{mg} / \mathrm{d}$ ). Of the 40 patients, $29(72.5 \%)$ received benzodiazepines (Val/Val: $\mathrm{n}=18$ (5-18.3 mg/d), Val/Met: n=9 (4.2-22.5 mg/d), Met/Met: $\mathrm{n}=2$ $(5 \mathrm{mg} / \mathrm{d})$ (doses were converted to diazepam equivalents) and $10(25 \%)$ received biperiden (Val/Val: $\mathrm{n}=6(2-3 \mathrm{mg} / \mathrm{d})$, Val/Met: $n=4(1-4 \mathrm{mg} / \mathrm{d})$, Met/Met: $\mathrm{n}=0)$. In responders, aripiprazole decreased plasma levels of HVA ( $p=0.015)$, whereas the drug did not change plasma HVA levels $(p=0.418)$ in nonresponders. The plasma levels of MHPG decreased in both responders $(p=0.001)$ and nonresponders $(p=0.038)$. Of the 40 patients, 23 patients were homozygous for $\mathrm{Val}, 13$ were heterozygous, and 4 were homozygous for Met. The allele distribution was in Hardy-Weinberg equilibrium $\left(\chi^{2}=0.98\right.$, $d f=1, p>0.05$ ). At baseline, no significant differences in PANSS scores, CGI-S, or plasma levels of monoamine metabolites were found (Table 1).

The responder rate to aripiprazole did not differ among the 3 genotype groups $(p=0.157)$ (Table 1). Repeatedmeasures ANOVA revealed significant time effects on PANSS total $(p<0.001)$ and positive $(p<0.001)$ and negative $(p<0.001)$ scores (Figure 1$)$. There was significant genotype-time interactions on PANSS total $(p=0.009)$ and general psychopathology ( $p=0.007)$ scores, with Met/Met genotype showing greater improvement (Figure 1). We also found a trend level genotype-time interaction in the PANSS negative score $(p=0.065)$.

We found a significant time effect on plasma MHPG levels ( $p=0.009$ ), but no time effect was found for plasma HVA levels $(p=0.756)$ or time-genotype interactions on plasma levels of HVA ( $p=0.21)$ or MHPG $(p=0.47)$.

\section{Discussion}

To the best of our knowledge, this is the first study to investigate the effects of the Val 108/158 Met polymorphism in
Table I Comparisons among the 3 genotypes

\begin{tabular}{|c|c|c|c|c|}
\hline Genotype & $\begin{array}{l}\text { Val/Val } \\
\text { group } \\
(n=23)\end{array}$ & $\begin{array}{l}\text { Val/Met } \\
\text { group } \\
(n=\mid 3)\end{array}$ & $\begin{array}{l}\text { Met/Met } \\
\text { group } \\
(n=4)\end{array}$ & $p$-value \\
\hline \multicolumn{5}{|l|}{ At baseline } \\
\hline Age (years) & $41.6 \pm 11.9$ & $43.5 \pm 14.2$ & $35.7 \pm 2.1$ & $0.62 I^{a}$ \\
\hline Sex, male/female & $13 / 10$ & $9 / 4$ & $3 / 1$ & $0.648^{\mathrm{b}}$ \\
\hline $\begin{array}{l}\text { Duration of illness } \\
\text { (years) }\end{array}$ & $10.0 \pm 9.6$ & $13.7 \pm 14.2$ & $8.0 \pm 7.0$ & $0.576^{a}$ \\
\hline PANSS total & $105.1 \pm 13.2$ & $109.5 \pm 15.1$ & $113.8 \pm 10.6$ & $0.412^{\mathrm{a}}$ \\
\hline PANSS positive & $28.1 \pm 4.9$ & $28.5 \pm 3.5$ & $27.3 \pm 2.5$ & $0.867^{a}$ \\
\hline PANSS negative & $23.8 \pm 5.6$ & $24.8 \pm 6.4$ & $28.3 \pm 6.5$ & $0.390^{a}$ \\
\hline PANSS general & $53.2 \pm 7.7$ & $55.9 \pm 9.3$ & $59.5 \pm 7.2$ & $0.305^{\mathrm{a}}$ \\
\hline CGI-severity & $5.5 \pm 0.5$ & $5.5 \pm 0.8$ & $5.5 \pm 0.6$ & $0.983^{\mathrm{a}}$ \\
\hline $\begin{array}{l}\text { Plasma HVA level } \\
(\mathrm{ng} / \mathrm{mL})\end{array}$ & $17.0 \pm 7.1$ & $19.1 \pm 7.9$ & $|4| \pm 5.6$. & $0.455^{\mathrm{a}}$ \\
\hline $\begin{array}{l}\text { Plasma MHPG } \\
\text { level ( } \mathrm{ng} / \mathrm{mL})\end{array}$ & $11.3 \pm 5.3$ & $13.9 \pm 7.6$ & $7.9 \pm 3.3$ & $0.195^{\mathrm{a}}$ \\
\hline \multicolumn{5}{|l|}{ At endpoint } \\
\hline $\begin{array}{l}\text { Dose of } \\
\text { aripiprazole }(\mathrm{mg} / \mathrm{d})\end{array}$ & $22.0 \pm 7.4$ & $26.8 \pm 4.0$ & $26.0 \pm 3.5$ & $0.097^{a}$ \\
\hline $\begin{array}{l}\text { Responders/ } \\
\text { nonresponders }\end{array}$ & $10 / 13$ & $3 / 10$ & $3 / 1$ & $0.157^{b}$ \\
\hline PANSS total & $83.5 \pm 17.8$ & $92.2 \pm 22.1$ & $67.3 \pm 24.0$ & $0.094^{a}$ \\
\hline PANSS positive & $20.6 \pm 6.5$ & $23.0 \pm 7.0$ & $14.8 \pm 5.9$ & $0.107^{a}$ \\
\hline PANSS negative & $20.6 \pm 5.5$ & $22.2 \pm 6.8$ & $20.3 \pm 9.2$ & $0.734^{a}$ \\
\hline PANSS general & $42.3 \pm 8.1$ & $46.9 \pm 11.8$ & $33.3 \pm 12.3$ & $0.058^{\mathrm{a}}$ \\
\hline CGI-severity & $3.8 \pm \mathrm{I} .4$ & $4.2 \pm 1.4$ & $2.5 \pm 1.7$ & $0.119^{a}$ \\
\hline CGI-improvement & $2.7 \pm 1.1$ & $3.0 \pm 1.1$ & $1.5 \pm 1.0$ & $0.06 \mathrm{I}^{\mathrm{a}}$ \\
\hline $\begin{array}{l}\text { Plasma HVA level } \\
(\mathrm{ng} / \mathrm{mL})\end{array}$ & $16.8 \pm 11.0$ & $15.4 \pm 7.4$ & $19.6 \pm 10.6$ & $0.759^{a}$ \\
\hline $\begin{array}{l}\text { Plasma MHPG } \\
\text { level }(\mathrm{ng} / \mathrm{mL})\end{array}$ & $7.9 \pm 3.3$ & $8.6 \pm 3.9$ & $6.5 \pm 1.9$ & $0.552^{\mathrm{a}}$ \\
\hline
\end{tabular}

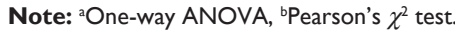

Abbreviations: PANSS, Positive and Negative Syndrome Scale; CGI, Clinical Global Impression; HVA, homovanillic acid; ANOVA, analysis of variance.

COMT on treatment response to aripiprazole and plasma monoamine metabolite levels in patients with acute schizophrenia. Although the responder rate did not differ among the 3 genotype groups, we found a significant association between the Val 108/158 Met polymorphism and the improvement in PANSS score after the treatment with aripiprazole. On the other hand, no significant genetic effects were found on plasma levels of monoamine metabolites during treatment.

Our results showing a significant relationship between the Met/Met genotype and greater improvement in PANSS score are consistent with a recent meta-analysis ${ }^{4}$ demonstrating that Met/Met individuals show significantly greater improvements than Val carriers, although the meta-analysis included studies of typical and atypical antipsychotics, but not aripiprazole. Notably, the meta-analysis reported no significant associations between the Val 108/158 Met 


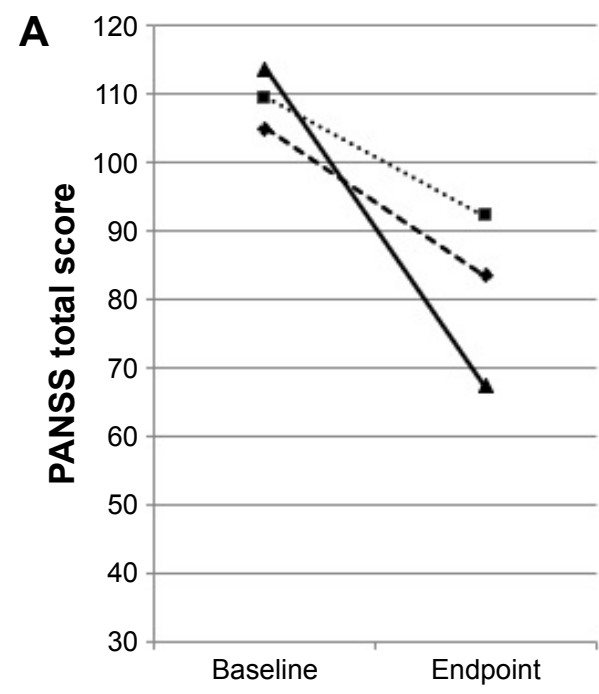

B
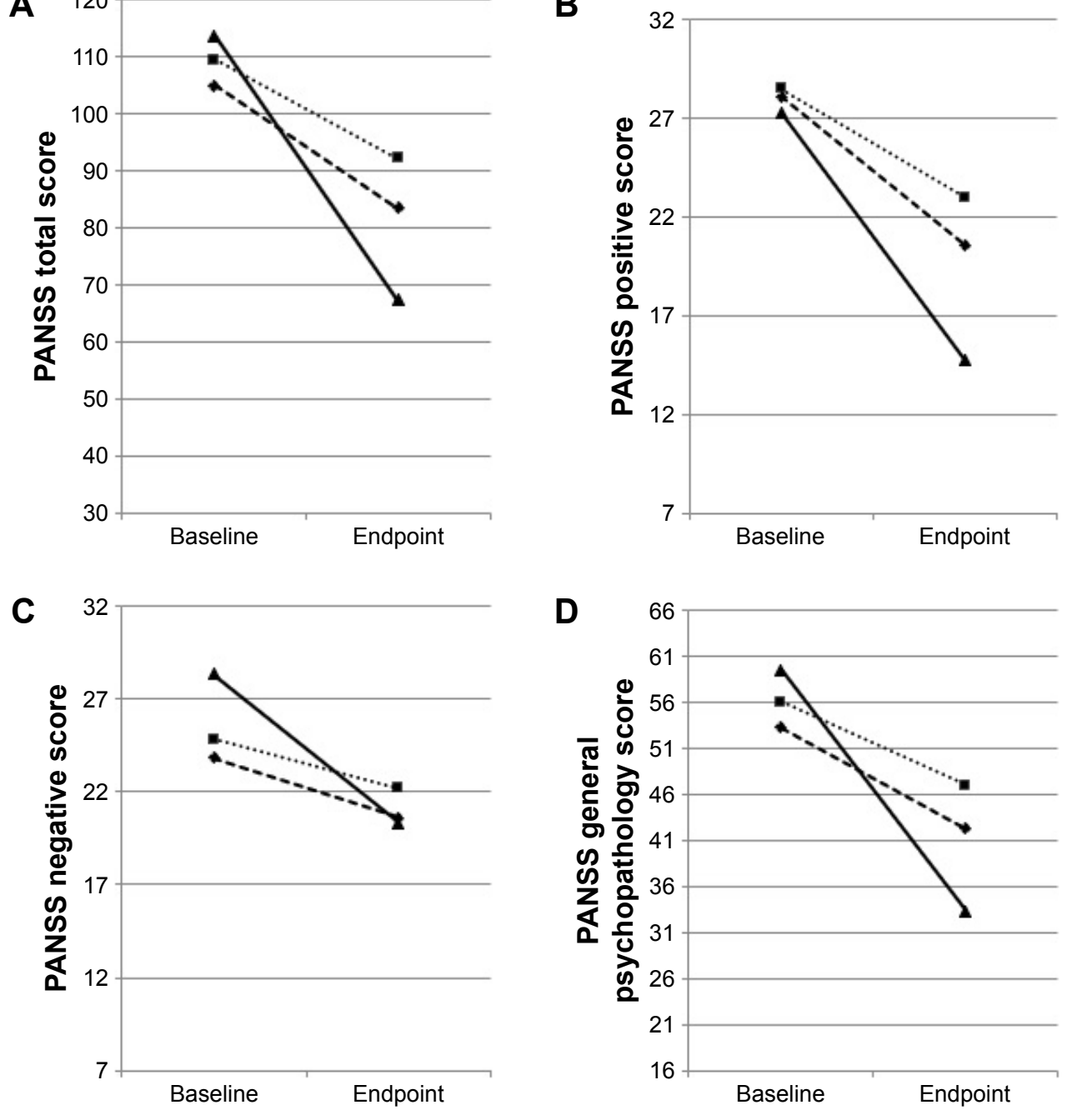

Val/Met

Met/Met

Figure I A mean change in PANSS total, positive, negative, and general psychopasology scores at baseline and 6 weeks.

Notes: $(\mathbf{A})$ Genotype $\times$ time interaction on PANSS total score $(F=5.296 ; p=0.009)$. (B) Genotype $\times$ time interaction on PANSS positive score $(F=2.493 ; p=0.096)$. (C) Genotype $\times$ time interaction on PANSS negative score $(F=2.94 I$; $p=0.065)$. (D) Genotype $\times$ time interaction on PANSS general $p s y c h o p a t h o l o g y$ score $(F=5.74 I ; p=0.007)$.

Abbreviation: PANSS, Positive and Negative Syndrome Scale.

polymorphism and treatment response in patients treated with typical antipsychotics. Although aripiprazole has a different pharmacological profile than other antipsychotics as a partial agonist for DRD2, aripiprazole is classified as an atypical antipsychotic drug, and our results support the results of Huang et al. ${ }^{4}$

The difference in treatment response among the genotypes may be partially explained by the enzyme activity of COMT. The activity of the Val allele enzyme is 3- to 4-fold higher than that of the Met allele enzyme. ${ }^{6}$ If individuals with the Met/Met genotype have lower COMT activity, dopamine will not be metabolized sufficiently, which may lead to hyperdopaminergic neurotransmission. In such a case, antipsychotics may inhibit the hyperdopaminergic state with antagonism for DRD2 in the mesolimbic system more effectively in the acute phase of schizophrenia, although we found no significant genotype-time interaction on PANSS positive score. Furthermore, the inverted U-curve hypothesis of dopamine function suggests that too much dopamine activity in the prefrontal cortex impairs working memory performance, whereas hypofunction of dopamine leads to cognitive dysfunction in patients with schizophrenia. ${ }^{21}$ Atypical antipsychotics including aripiprazole have inhibitory effects on DRD2 and 5-HT2A receptors, which may be related to appropriate dopamine neurotransmission in the prefrontal cortex. On the other hand, typical antipsychotics inhibit DRD2 but not 5-HT2A receptors, which may induce hypofunction of dopamine. Additionally, aripiprazole is a partial agonist 
for DRD2, which may also stabilize dopamine function in the prefrontal cortex. Taken together, favorable response to aripiprazole in patients with the Met/Met genotype may be explained by stabilizing dopamine function in the prefrontal cortex, which leads to improve cognitive function.

In this study, the Val 108/158 Met polymorphism was not associated with changes in plasma levels of monoamine metabolites. Previous studies had reported that the Val 108/158 Met polymorphism is not associated with monoamine metabolites levels in cerebrospinal fluid ${ }^{22-24}$ or plasma, ${ }^{25-27}$ although no studies examined the association between the polymorphism and changes in levels of monoamine metabolites during treatment with antipsychotics. Our results suggest that the Val 108/158 Met polymorphism may not be related to changes in plasma levels of HVA or MHPG after aripiprazole treatment in schizophrenia. We previously reported associations between variants in DRD2 and plasma levels of monoamine metabolites, ${ }^{17,28}$ suggesting that Taq1A polymorphism in DRD2 may have effects on plasma HVA levels. ${ }^{17}$ COMT metabolizes dopamine and other monoamines and is not directly affected by antipsychotics. Therefore, the Val 108/158 Met polymorphism may not have effects on plasma levels of HVA or MHPG as do DRD2 polymorphisms.

Our study has several limitations. First, our sample size was very small, and there were only 4 subjects in Met/Met genotype group. This limitation restricts our preliminary results. Second, this study included both first-episode and recurrent patients. Recurrent patients may be influenced by previous treatment effects such as upregulation of D2 receptors. Third, this study focused on only a COMT polymorphism, and we did not examine gene-gene interactions. Finally, we did not examine cognitive functions such as working memory with a neuropsychological test battery. Nevertheless, this is the first study to investigate the effects of the Val 108/158 Met polymorphism in COMT on treatment response to aripiprazole, and our results showed that individuals with the Met/Met genotype had greater improvement in PANSS score after the treatment. Further studies should investigate the underlying biological mechanism of the association between the Met/Met genotype and a favorable response to antipsychotics.

\section{Conclusion}

We found a significant association between the Val 108/158 Met polymorphism in COMT and the improvement in PANSS score after the treatment with aripiprazole. Although the responder rate did not differ among the 3 genotype groups, individuals with the Met/Met genotype had greater improvement in PANSS score after the treatment. On the other hand, the Val 108/158 Met polymorphism may not affect plasma levels of HVA or MHPG. Caution is needed when interpreting our results because of the small sample size and heterogeneity among patients. Additional studies with a larger sample size are needed to confirm and extend our results.

\section{Acknowledgment}

The authors thank Kazuko Kanno for help with running polymerase chain reaction experiments.

\section{Disclosure}

The authors report no conflicts of interest in this work.

\section{References}

1. Zhang JP, Lencz T, Malhotra AK. D2 receptor genetic variation and clinical response to antipsychotic drug treatment: a meta-analysis. Am J Psychiatry. 2010;167(7):763-772.

2. Arranz MJ, Munro J, Sham P, et al. Meta-analysis of studies on genetic variation in 5-HT2A receptors and clozapine response. Schizophr Res. 1998;32(2):93-99.

3. Takekita Y, Fabbri C, Kato M, et al. HTR1A polymorphisms and clinical efficacy of antipsychotic drug treatment in schizophrenia: a metaanalysis. Int J Neuropsychopharmacol. 2016;19(5):pii: pyv125.

4. Huang E, Zai CC, Lisoway A, et al. Catechol-O-methyltransferase Val158Met polymorphism and clinical response to antipsychotic treatment in schizophrenia and schizo-affective disorder patients: a metaanalysis. Int J Neuropsychopharmacol. 2016;19(5):pii: pyv132.

5. Baker K, Baldeweg T, Sivagnanasundaram S, Scambler P, Skuse D. COMT Val108/158Met modifies mismatch negativity and cognitive function in 22q11 deletion syndrome. Biol Psychiatry. 2005;58(1): 23-31.

6. Woo JM, Yoon KS, Yu BH. Catechol O-methyltransferase genetic polymorphism in panic disorder. Am J Psychiatry. 2002;159(10): $1785-1787$.

7. Bertolino A, Caforio G, Blasi G, et al. Interaction of COMT Val108/158 Met genotype and olanzapine treatment on prefrontal cortical function in patients with schizophrenia. Am J Psychiatry. 2004; 161(10):1798-1805.

8. Bertolino A, Caforio G, Blasi G, et al. COMT Val158Met polymorphism predicts negative symptoms response to treatment with olanzapine in schizophrenia. Schizophr Res. 2007;95(1-3):253-255.

9. Weickert WT, Goldberg ET, Mishara A, et al. Catechol-O-methyltransferase Val108/158Met genotype predicts working memory response to antipsychotic medications. Biol Psychiatry. 2004;56(9):677-682.

10. Woodward ND, Jayathilake K, Meltzer HY. COMT val108/158met genotype, cognitive function, and cognitive improvement with clozapine in schizophrenia. Schizophr Res. 2007;90(1-3):86-96.

11. Yamanouchi Y, Iwata N, Suzuki T, Kitajima T, Ikeda M, Ozaki N. Effect of DRD2, 5-HT2A, and COMT genes on antipsychotic response to risperidone. Pharmacogenomics J. 2003;3(6):356-361.

12. Pelayo-Terán JM, Pérez-Iglesias R, Vázquez-Bourgon J, et al. CatecholO-methyltransferase Val158Met polymorphism and negative symptoms after acute antipsychotic treatment in first-episode non-affective psychosis. Psychiatry Res. 2011;185(1-2):286-289.

13. Tybura P, Samochowiec A, Beszlej A, et al. Some dopaminergic genes polymorphisms are not associated with response to antipsychotic drugs in schizophrenic patients. Pharmacol Rep. 2012;64(3):528-535. 
14. Bishop JR, Reilly JL, Harris MS, et al. Pharmacogenetic associations of the type-3 metabotropic glutamate receptor (GRM3) gene with working memory and clinical symptom response to antipsychotics in first-episode schizophrenia. Psychopharmacology (Berl). 2015;232(1):145-154.

15. Maas JW, Hattox SE, Greene NM, Landis DH. Estimates of dopamine and serotonin synthesis by the awake human brain. JNeurochem. 1980; 34(6):1547-1549.

16. Kopin IJ, Gordon EK, Jimerson DC, Polinsky RJ. Relation between plasma and cerebrospinal fluid levels of 3-methoxy-4-hydroxyphenylglycol. Science. 1983;219(4580):73-75.

17. Miura I, Takeuchi S, Katsumi A, et al. Effects of aripiprazole and the Taq1A polymorphism in the dopamine D2 receptor gene on the clinical response and plasma monoamine metabolites level during the acute phase of schizophrenia. J Clin Psychopharmacol. 2012;32(1): 106-109.

18. Nagaoka S, Iwamoto N, Arai H. First-episode neuroleptic-free schizophrenics: concentrations of monoamines and their metabolites in plasma and their correlations with clinical responses to haloperidol treatment. Biol Psychiatry. 1997;41(8):857-864.

19. Watanabe K, Miura I, Kanno-Nozaki K, et al. Associations between five-factor model of the Positive and Negative Syndrome Scale and plasma levels of monoamine metabolite in patients with schizophrenia. Psychiatry Res. 2015;230(2):419-423.

20. Li T, Sham PC, Vallada H, et al. Preferential transmission of the high activity allele of COMT in schizophrenia. Psychiatr Genet. 1996;6(3): 131-133.

21. Williams GV, Castner SA. Under the curve: critical issues for elucidating D1 receptor function in working memory. Neuroscience. 2006;139(1): $263-276$.
22. Jönsson EG, Goldman D, Spurlock G, et al. Tryptophan hydroxylase and catechol-O-methyltransferase gene polymorphisms: relationships to monoamine metabolite concentrations in CSF of healthy volunteers. Eur Arch Psychiatry Clin Neurosci. 1997;247(6):297-302.

23. Zalsman G, Huang YY, Harkavy-Friedman JM, Oquendo MA, Ellis SP, Mann JJ. Relationship of MAO-A promoter (u-VNTR) and COMT (V158M) gene polymorphisms to CSF monoamine metabolites levels in a psychiatric sample of caucasians: a preliminary report. Am J Med Genet B Neuropsychiatr Genet. 2005;132B(1):100-103.

24. Andreou D, Söderman E, Axelsson T, et al. Polymorphisms in genes implicated in dopamine, serotonin and noradrenalin metabolism suggest association with cerebrospinal fluid monoamine metabolite concentrations in psychosis. Behav Brain Funct. 2014;10:26.

25. Köhnke MD, Wiatr G, Kolb W, et al. Plasma homovanillic acid: a significant association with alcoholism is independent of a functional polymorphism of the human catechol-O-methyltransferase gene. Neuropsychopharmacology. 2003;28(5):1004-1010.

26. Dávila R, Zumárraga M, Basterreche N, Arrúe A, Zamalloa MI, Anguiano JB. Influence of the catechol-O-methyltransferase Val108/158Met polymorphism on the plasma concentration of catecholamine metabolites and on clinical features in type I bipolar disordera preliminary report. J Affect Disord. 2006;92(2-3):277-281.

27. Basterreche N, Dávila R, Zumárraga M, et al. Biological correlates of the congruence and incongruence of psychotic symptoms in patients with type 1 bipolar disorder. Neuropsychobiology. 2008;58(3-4):111-117.

28. Miura I, Kanno-Nozaki K, Hino M, et al. Influence of -141C Ins/Del polymorphism in DRD2 gene on clinical symptoms and plasma homovanillic acid levels in the treatment of schizophrenia with aripiprazole. J Clin Psychopharmacol. 2015;35(3):333-334. 


\section{Supplementary material}

Table SI Comparisons between responders and nonresponders

\begin{tabular}{|c|c|c|c|}
\hline Response & $\begin{array}{l}\text { Responders } \\
(n=16)\end{array}$ & $\begin{array}{l}\text { Nonresponders } \\
(n=24)\end{array}$ & $p$-value \\
\hline \multicolumn{4}{|l|}{ At baseline } \\
\hline Age (years) & $40.3 \pm 12.0$ & $42.9 \pm 12.1$ & $0.644^{\mathrm{a}}$ \\
\hline Sex, male/female & $8 / 8$ & $17 / 7$ & $0.182^{b}$ \\
\hline Duration of illness (years) & $|1.8 \pm 11|$. & $10.9 \pm 11.2$ & $0.98 I^{\mathrm{a}}$ \\
\hline PANSS total & $107.1 \pm 9.2$ & $107.6 \pm 16.1$ & $0.053^{\mathrm{a}}$ \\
\hline PANSS positive & $27.5 \pm 3.8$ & $28.6 \pm 4.5$ & $0.750^{\mathrm{a}}$ \\
\hline PANSS negative & $24.9 \pm 4.2$ & $24.4 \pm 6.9$ & $0.080^{\mathrm{a}}$ \\
\hline PANSS general & $54.6 \pm 7.3$ & $54.8 \pm 9.0$ & $0.359^{a}$ \\
\hline CGI-severity & $5.6 \pm 0.5$ & $5.5 \pm 0.7$ & $0.214^{a}$ \\
\hline Plasma HVA level (ng/mL) & $17.1 \pm 6.5$ & $17.6 \pm 7.8$ & $0.466^{\mathrm{a}}$ \\
\hline Plasma MHPG level (ng/mL) & $11.5 \pm 6.0$ & $12.0 \pm 6.3$ & $0.608^{\mathrm{a}}$ \\
\hline \multicolumn{4}{|l|}{ At endpoint } \\
\hline Dose of aripiprazole (mg/d) & $21.3 \pm 6.2$ & $26.4 \pm 5.7$ & $0.618^{\mathrm{a}}$ \\
\hline Genotype groups (ValVal/ValMet/MetMet) & $10 / 3 / 3$ & $13 / 10 / 1$ & $0.157^{b}$ \\
\hline PANSS total & $67.8 \pm 10.1$ & $96.0 \pm 17.9$ & $0.046^{\mathrm{a}}$ \\
\hline PANSS positive & $15.1 \pm 3.2$ & $24.5 \pm 5.9$ & $0.009^{\mathrm{a}}$ \\
\hline PANSS negative & $17.8 \pm 2.9$ & $23.3 \pm 6.9$ & $0.020^{\mathrm{a}}$ \\
\hline PANSS general & $34.9 \pm 5.5$ & $48.3 \pm 9.2$ & $0.056^{\mathrm{a}}$ \\
\hline CGI-severity & $2.6 \pm 0.7$ & $4.7 \pm 1.2$ & $0.006^{a}$ \\
\hline CGI-improvement & $1.5 \pm 0.5$ & $3.5 \pm 0.5$ & $0.000^{\mathrm{a}}$ \\
\hline Plasma HVA level (ng/mL) & $12.7 \pm 3.7$ & $19.3 \pm 11.5$ & $0.006^{a}$ \\
\hline Plasma MHPG level (ng/mL) & $6.3 \pm 1.8$ & $9.1 \pm 3.8$ & $0.004^{\mathrm{a}}$ \\
\hline
\end{tabular}

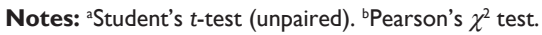

Abbreviations: PANSS, Positive and Negative Syndrome Scale; CGI, Clinical Global Impression; HVA, homovanillic acid.

\section{Publish your work in this journal}

Neuropsychiatric Disease and Treatment is an international, peerreviewed journal of clinical therapeutics and pharmacology focusing on concise rapid reporting of clinical or pre-clinical studies on a range of neuropsychiatric and neurological disorders. This journal is indexed on PubMed Central, the 'PsycINFO' database and CAS, and is the official journal of The International Neuropsychiatric Association (INA). The manuscript management system is completely online and includes a very quick and fair peer-review system, which is all easy to use. Visit http://www.dovepress.com/testimonials.php to read real quotes from published authors. 